\title{
Addition of Carboxylic Acids Using Chiral Lithium Amides as Auxiliaries
}

\section{Key words}

lithium

amides

Michael addition

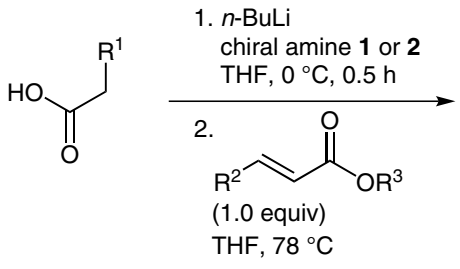<smiles>[R]C(CC(=O)O[10OH])C([R])C(=O)O</smiles>

$27-97 \%$ yield dr up to $>30: 1$ up to $97 \%$ ee

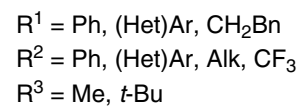

Selected examples:

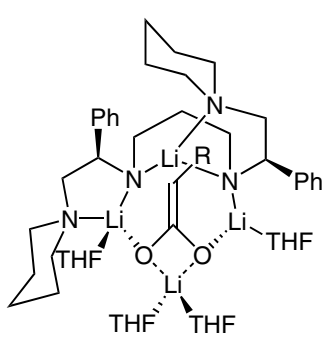

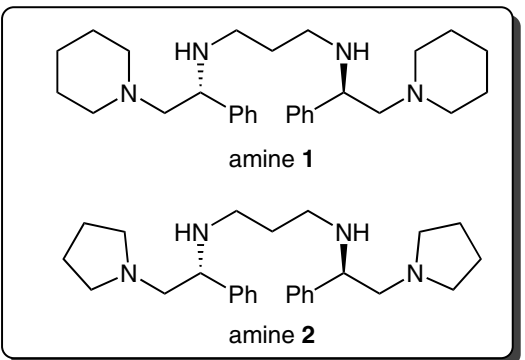

aggregate formation of the carboxylic acid and chiral amine 1<smiles>COc1ccc(C(CC(C)=O)C(C(C)=O)c2ccccc2)cc1</smiles>

$74 \%$ yield $\mathrm{dr}=30: 1,75 \%$ ee (amine 1)<smiles>CCOC(=O)C[C@@H](CC)C(C(=O)O)c1ccccc1</smiles>

$72 \%$ yield

$\mathrm{dr}=5: 1,84 \%$ ee (amine 2)<smiles>CC(=O)CC(c1cc2ccccc2o1)C(C(=O)O)c1ccccc1</smiles>

$>30: 1,73 \%$ ee (amine 1)<smiles>CC(=O)CC(c1ccccc1)C(C(=O)O)C(F)(F)F</smiles>

$87 \%$ yield $\mathrm{dr}>30: 1,58 \%$ ee (amine 1)<smiles>CC(=O)CC(c1cnoc1C)C(C(=O)O)c1ccccc1</smiles>

$54 \%$ yield $\mathrm{dr}>30: 1,86 \%$ ee (amine 1)<smiles>CC(=O)CC(c1cccnc1)[C@H](C(=O)O)c1ccc(Br)cc1</smiles>

$63 \%$ yield $\mathrm{dr}=8: 1,763 \%$ ee (amine 1)<smiles>CC(=O)CC(C1CC1)C(C(=O)O)c1ccccc1</smiles>

$78 \%$ yield

$\mathrm{dr}=5: 1,85 \%$ ee (amine 2)<smiles>CC(=O)CC(c1ccccc1)[C@H](C(=O)O)c1cccs1</smiles>

$83 \%$ yield $\mathrm{dr}>30: 1,94 \%$ ee (amine 1)
Significance: Zakarian and co-workers report the direct enantioselective Michael addition of carboxylic acids to $\alpha, \beta$-usaturated esters using chiral lithium amides as traceless auxiliaries.
Comment: The chiral reagents can be readily recovered in 99\% yield by extraction with aqueous acid. Additionally, this protocol has been applied to the enantioselective total synthesis of the presumed structure of pulveraven B.

SYNFACTS Contributors: Paul Knochel, Diana Haas

Synfacts 2015, 11(4), 0415 Published online: 18.03.2015

Dol: 10.1055/s-0034-1380309; Reg-No.: P02015SF 